\title{
Chlorate Resistance and Nitrate Assimilation in Industrial Strains of Penicillium chrysogenum
}

\author{
By J. A. BIRKETT* AND R. T. ROWLANDS \\ Glaxo Operations UK Ltd, Ulverston, Cumbria LA12 9DR
}

(Received 10 November 1980)

\begin{abstract}
Several chlorate-resistant mutants of Penicillium chrysogenum were isolated and analysed; all were affected in nitrate assimilation. Nine loci were recognized by complementation analysis and these appear to be equivalent to the niaD (nitrate reductase structural gene), nir $A$ (control locus) and seven cnx loci (responsible for the biosynthesis of a cofactor for nitrate reductase) of Aspergillus nidulans. The organization of the nitrate assimilation genes appears to be similar in both organisms, even to the extent of having contiguous genes coding for the nitrate and nitrite reductase enzymes.
\end{abstract}

\section{INTRODUCTION}

Chlorate toxicity and mutations conferring resistance have been studied in fungi (Lewis \& Fincham, 1970; Cove, 1976a, b), algae (Nichols \& Syrett, 1978; Huskey et al., 1979) and bacteria (Stouthamer, 1967; Piéchaud et al., 1967). In all these studies a loss of nitrate reductase activity was identified as one cause of chlorate resistance.

The most extensive genetical studies have been carried out with Aspergillus nidulans (Cove, $1976 a, b)$. These studies suggested that the toxic effects of chlorate probably resulted from its activity as a non-metabolizable analogue of nitrate. Mutations in at least ten genes (twelve loci) in $A$. nidulans can produce a chlorate-resistant phenotype; seven of these genes (nine loci) are involved in the production of an active nitrate reductase (Cove, 1976 b). One is the structural gene for nitrate reductase (niaD), one (nirA) is believed to code for a regulatory element needed for the synthesis of nitrate and nitrite reductase, and the remaining five (cnxA, $B, C, E, F, G, H)$ are involved in the synthesis of a cofactor shared with xanthine dehydrogenase (Pateman et al., 1964, 1967; Pateman \& Cove, 1967; Cove, 1970, 1976b; Scazzocchio, 1974).

A spergillus nidulans has often been used to study problems that have industrial significance especially in relation to penicillin production (Holt \& Macdonald, 1968a, b; Edwards et al., 1974; Merrick, 1975 a, b; Merrick \& Caten, 1975a, b; Ditchburn et al., 1976; Simpson \& Caten, 1979). The present paper reports a study of chlorate resistance in high-yielding strains of Penicillium chrysogenum which has been carried out to determine if there are any similarities in the control of nitrate assimilation in the two organisms. Such comparison could provide a useful insight into how applicable are the studies with $A$. nidulans.

\section{METHODS}

Strains. The strains of $P$. chrysogenum used in these studies were derived from Q176 (Stauffer \& Backus, 1954) by serial mutation and selection for increased penicillin production.

Media and genetical techniques. The media and methods used were similar to those of Macdonald et al. (1963a, $b, c)$ and Ball (1971) but with the following exceptions. The basal medium used to study the assimilation of different nitrogen sources was a modified Czapek-Dox medium, similar to that used by Macdonald et al. (1963a, $b, c)$ but with $\mathrm{NaCl}$ replacing the $\mathrm{NaNO}_{3}$. The mutants were replicated on to the test media using the methods of 
Roberts (1959). Nitrogen sources were added to the basal medium to give the following concentrations: $\mathrm{NaNO}_{3}$, $12 \mathrm{~mm}$; $\mathrm{NaNO}_{2}, 1.5 \mathrm{~mm}$; $\left(\mathrm{NH}_{4}\right)_{2} \mathrm{SO}_{4}, 0.8 \mathrm{~mm}$; adenine hydrochloride, $0.6 \mathrm{~mm}$; L-arginine, $6 \mathrm{~mm}$; uric acid, $0.6 \mathrm{~mm}$.

Isolation of mutants. Mutants were isolated spontaneously, or after ultraviolet light induction, by plating spores on to basal medium with $94 \mathrm{~mm}-\mathrm{NaClO}_{3}$ and a suitable nitrogen source. The strains were irradiated with ultraviolet light to give approximately $10 \%$ survival.

Classification of mutants. The mutants were grouped into four classes using two criteria - their growth responses on media containing nitrate, nitrite or adenine as sole nitrogen source, and their degree of resistance to chlorate. Adenine was used in preference to hypoxanthine (Cove, 1976a) because the former is more soluble and the differing growth responses were easier to distinguish.

\section{RESULTS}

Growth responses of the mutants. The four mutant classes (Cove, 1976 $a, b$ ) were as follows. (1) nia mutants: these showed very sparse growth on nitrate, similar to that on medium without added nitrogen sources. The degree of chlorate resistance varied from mutant to mutant, some being weaker than others. (2) cnx mutants: these showed very sparse growth on nitrate and much reduced growth on adenine. There was some variation in chlorate resistance, as with nia mutants. (3) nir mutants: these showed more growth on nitrate than nia and cnx mutants, but less than the wild-type; growth on nitrite was reduced, but better than on nitrate. These mutants were weakly resistant to chlorate, responding like the weaker nia and cnx mutants. (4) niinia mutants: these were relatively rare. All gave very sparse growth on nitrate and nitrite, and a strong response on chlorate.

Molybdate repair. The $c n x$ mutants were tested on medium containing $33 \mathrm{~mm}$-molybdate with nitrate as sole nitrogen source. The growth of one mutant $(c n x-7)$ was restored to the wild-type level on this medium.

Nitrite toxicity. The growth of the nir mutants was inhibited by $10 \mathrm{~mm}$-nitrite even when $5 \mathrm{~mm}$-urea or $10 \mathrm{~mm}$-ammonium was present as an alternative nitrogen source. The niinia mutants responded similarly on $10 \mathrm{~mm}$-nitrite and $5 \mathrm{~mm}$-urea but grew more strongly on $10 \mathrm{~mm}$-nitrite and $10 \mathrm{~mm}$-ammonium although there was still some inhibition of growth. The cnx- 6 mutant gave an unexpected response on these two media; its growth was inhibited in the presence of ammonium but not of urea. The possibility that this strain could be a double mutant is under investigation.

Specificity effects. For these analyses, niinia-like mutants were grouped with nia mutants. There was no significant difference ( $\chi^{2}$ test, $95 \%$ level) in the distribution of mutant types isolated either on L-arginine or on uric acid as sole nitrogen source (Table 1). There did appear to be a difference in the distribution of types isolated before and after far ultraviolet mutagenesis (Table 2). The results in Table 2 are from several experiments independently conducted in an effort to remove any clonal distortions from the spontaneous data.

Complementation studies. The following mutants were used for complementation studies: nia-1 to 4 , nir-1 to 4, cnx-1 to 14 , and one niinia. 'Pair-wise' combinations of the mutants were randomly selected and tested for their complementation reaction. The results

Table 1. Distribution of mutant types isolated on different nitrogen sources

$\begin{array}{lcc}\text { Mutant type } & \begin{array}{c}\text { Distribution on } \\ \text { L-arginine } \\ (\%)\end{array} & \begin{array}{c}\text { Distribution on } \\ \text { uric acid } \\ (\%)\end{array} \\ \text { nia } & 46 & \\ \text { cnx } & 46 & 43 \\ \text { nir } & 40 & 31 \\ \text { CRUN } & 14 & 26 \\ \text { Total no. tested } & 0 & 0 \\ & 74 & 63\end{array}$


Table 2. Comparison of mutant types isolated before and after mutagenesis

$\begin{array}{lcccc}\text { Mutant type } & \overbrace{\begin{array}{c}\text { No. } \\ \text { isolated }\end{array}}^{\begin{array}{c}\text { Distribution } \\ (\%)\end{array}} & \overbrace{\begin{array}{c}\text { No. } \\ \text { isolated }\end{array}}^{\text {Spontaneous mutants }} & \text { Dibution } \\ \text { nia } & 13 & 28 & 235 & 41 \\ \text { cnx } & 27 & 57 & 221 & 39 \\ \text { nir } & 7 & 15 & 116 & 20\end{array}$

from these tests were used to draw up a short list of possible loci. Tester strains representing the recognized loci were then used in specific combinations to yield further information (Armitt et al., 1976). The results were interpreted thus:

(1) nia mutants. The four nia mutants tested did not complement with each other or with the niinia mutant but they did complement with the nir and $c n x$ mutants. This suggests that there is only one locus (niaA) and that the niinia mutant carries a lesion in this locus.

(2) nir mutants. Four nir mutants were tested. They did not complement with each other but did complement with the nia and $c n x$ mutants. This suggests that there is only one locus (nirA).

(3) cnx mutants. Some cnx mutants complemented with each other but others did not. On this basis they could be split into seven complementation groups: $c n x A 2,4 ; \operatorname{cn} x B 1,6,11$; cnxC3; cnxD10; cnxE7; cnxF8; cnxG13. Une group gave the non-standard complementation pattern observed with the $c n x A, c n x B, c n x C$ loci of $A$. nidulans (Cove \& Pateman, 1963; Rever, 1965). Within this group the $c n x B$ mutants did not complement with the $c n x A$ and cnxC mutants, but the last two did complement with each other.

(4) niinia mutants. The one niinia mutant failed to complement with the nia mutants but did complement with the nir and $c n x$ mutants. It carried one lesion in the niaA gene and, presumably, another in the nii gene (Cove, 1976a).

Map location. Of the nine loci, two have been allocated to linkage groups - niaA on linkage group III and $\operatorname{cnx} G$ on group I of Ball's (1971) map. The niinia double mutant has been demonstrated to segregate as a single mitotic unit (unpublished data), supporting the hypothesis that it is similar to the deletion mutants of $A$. nidulans (Cove, 1976a).

\section{DISCUSSION}

Cove (1976a) demonstrated that the nitrogen source in the medium had a profound effect upon the spectra of chlorate-resistant mutants isolated from $A$. nidulans. Using two contrasting nitrogen sources (L-arginine and uric acid), no difference could be detected in the distribution of mutant types from $P$. chrysogenum. Cove also reported that the spectra of types differed before and after mutagenesis. This appeared to be generally true of $P$. chrysogenum but, unlike $A$. nidulans, the relative frequency of its nia mutants increased after mutagenesis.

The general growth responses of the $P$. chrysogenum mutants were similar to those of mutants isolated from $A$. nidulans. Four types of mutant were recognized, corresponding to the nia, cnx, nir and niinia classes (Cove 1976a). The main difference was the complete lack of $P$. chrysogenum mutants that were resistant to chlorate and able to utilize nitrate as sole nitrogen source (CRUN mutants; Cove, 1976a). The cnxE mutants of A. nidulans are believed to have lost the ability to incorporate molybdenum into the nitrate reductase/ xanthine dehydrogenase cofactor. Such mutants can be repaired by incorporating high levels of molybdate in the medium (Arst et al., 1970). One mutant of $P$. chrysogenum, designated $c n x E 7$, behaved in an identical manner. 
It has been reported that the nirA and niiA (similar to niiAniaD) mutants of $A$. nidulans could be distinguished by their growth responses on medium containing $20 \mathrm{~mm}$-nitrite with $20 \mathrm{~mm}$-ammonium or $5 \mathrm{~mm}$-urea (Rand \& Arst, 1977; Rand, 1978). Growth of the nirA mutants is inhibited in the presence of ammonium or urea but that of the niiA mutants only in the presence of urea. A similar response was found with the P. chrysogenum mutants, the only differences being that slightly different levels of nitrite, ammonium and urea were needed and that the growth of the niinia mutants was not fully restored by ammonium.

The results from complementation analysis were identical to those reported for $A$. nidulans: a single nia locus, a group of mutants carrying a lesion in the nia gene and probably in the nii gene (the behaviour of these mutants was identical to that of the mutants of $A$. nidulans which carry a deletion extending from the niaD gene into the adjacent niiA gene), a single nir locus and seven $c n x$ loci with a group of three showing a complex complementation pattern.

The similarities in the genetical architecture of nitrate assimilation by $P$. chrysogenum and $A$. nidulans strengthen the link between these two groups of filamentous fungi. It would be interesting to see if the similarities in organization extend to other, more distantly related fungi.

We wish to thank Drs C. Ball and K. N. Rand for their helpful discussion and criticism, and we record our appreciation to Mr J. M. Hislop and Miss H. C. Longfellow for their technical assistance.

\section{REFERENCES}

Armitt, S., McCullough, W. \& Roberts, C. F. (1976). Analysis of acetate non-utilizing ( $a c u)$ mutants in Aspergillus nidulans. Journal of General Microbiology 92, 263-282.

Arst, H. N. JR, MacDonald, D. W. \& Cove, D. J. (1970). Molybdate metabolism in Aspergillus nidulans. I. Mutations affecting nitrate reductase and/or xanthine dehydrogenase. Molecular and General Genetics 108, 129-145.

BALl, C. (1971). Haploidization analysis in Penicillium chrysogenum. Journal of General Microbiology 66, 63-69.

Cove, D. J. (1970). Control of gene action in Aspergillus nidulans. Proceedings of the Royal Society B 176, 267-275.

Cove, D. J. (1976a). Chlorate toxicity in Aspergillus nidulans: the selection and characterisation of chlorate resistant mutants. Heredity 36, 191-203.

Cove, D. J. (1976b). Chlorate toxicity in Aspergillus nidulans: studies of mutants altered in nitrate assimilation. Molecular and General Genetics 146, 147-159.

Cove, D. J. \& Pateman, J. A. (1963). Independently segregating loci concerned with nitrate reductase activity in Aspergillus nidulans. Nature, London 198, 262-263.

Ditchburn, P., Holt, G. \& Macdonald, K. D. (1976). The genetic location of mutations increasing penicillin yield in Aspergillus nidulans. In Second International Symposium on the Genetics of Industrial Microorganisms, pp. 213-227. Edited by K. D. Macdonald. London: Academic Press.

Edwards, G. F. Stl., Holt, G. \& Macdonald, K. D. (1974). Mutants of Aspergillus nidulans impaired in penicillin biosynthesis. Journal of General Microbiology 84, 420-422.
Holt, G. \& Macdonald, K. D. (1968a). Penicillin production and its mode of inheritance in Aspergillus nidulans. Antonie van Leeuwenhoek 34, 409-416.

HolT, G. \& MACDONALD, K. D. (1968 b). Isolation of strains with increased penicillin yield after hybridisation in Aspergillus nidulans. Nature, London 219, 636-637.

Huskey, R. J., Semenkovich, C. F., Griffin, B. E., Cecil, P. O., Callahan, A. M., Chace, K. V. \& KIRK, D. L. (1979). Mutants of Volvox carteri affecting nitrogen assimilation. Molecular and General Genetics 169, 157-161.

Lewis, C. M. \& FinchaM, J. R. S. (1970). Genetics of nitrate reductase in Ustilago maydis. Genetical Research 16, 151-163.

Macdonald, K. D., Hutchinson, J. M. \& Gillet, W. A. $(1963 a)$. Isolation of auxotrophs of Penicillium chrysogenum and their penicillin yields. Journal of General Microbiology 33, 365-374.

Macdonald, K. D., Hutchinson, J. M. \& Gillet, W. A. $(1963 b)$. Heterokaryon studies and the genetic control of penicillin and chrysogenin production in Penicillium chrysogenum. Journal of General Microbiology 33, 375-383.

Macdonald, K. D., Hutchinson, J. M. \& Gillet, W. A. $(1963 c)$. Formation and segregation of heterozygous diploids between wild-type strain and derivatives of high penicillin yield in Penicillium chrysogenum. Journal of General Microbiology 33, 385-394.

MerRICK, M. J. (1975a). Hybridization and selection for increased penicillin titre in wild-type isolates of Aspergillus nidulans. Journal of General Microbiology 91, 278-286.

MERRICK, M. J. $(1975 b)$. The inheritance of penicillin titre in crosses between lines of Aspergillus nidulans 
selected for increased productivity. Journal of General Microbiology 91, 287-294.

Merrick, M. J. \& CATEN, C. E. (1975a). The design of fermentation and biological assay procedures for assessment of penicillin production in populations of Aspergillus nidulans. Journal of Applied Bacteriology 38, 121-131.

Merrick, M. J. \& Caten, C. E. $(1975 b)$. The inheritance of penicillin titre in wild-type isolates of Aspergillus nidulans. Journal of General Microbiology 86, 283-293.

Nichols, G. L. \& Syrett, P. J. (1978). Nitrate reductase deficient mutants of Chlamydomonas reinhardii. Isolation and genetics. Journal of General Microbiology 108, 71-77.

Pateman, J. A. \& Cove, D. J. (1967). Regulation of nitrate reduction in Aspergillus nidulans. Nature, London 215, 1234-1237.

Pateman, J. A., Cove, D. J., Rever, B. M. \& RoBERTS, D. B. (1964). A common cofactor for nitrate reductase and xanthine dehydrogenase which also regulates the synthesis of nitrate reductase. Nature, London 201, 58-60.

Pateman, J. A., Rever, B. M. \& Cove, D. J. (1967). Genetics and biochemical studies of nitrate reduction in Aspergillus nidulans. Biochemical Journal 104, 103-111.

Piéchaud, M., Puig, J., Pichinoty, F., Azoulay, E. \& LE MinoR, L. (1967). Mutation affectant la nitrate-réductase A et d'autre enzymes bactériennes d'oxydo-réduction. Etude preliminaire. Annales de l'Institut Pasteur 112, 24-37.
RAND, K. N. (1978). Aspects of the control of nitrogen metabolism in Aspergillus nidulans. Ph.D. thesis, University of Cambridge.

RAND, K. N. \& ARsT, H. N. JR (1977). A mutation in Aspergillus nidulans which affects the regulation of nitrite reductase and is tightly linked to its structural gene. Molecular and General Genetics 155, 67-75.

REVER, B. M. (1965). Biochemical and genetical studies of inorganic nitrogen metabolism in Aspergillus nidulans. Ph.D. thesis, University of Cambridge.

ROBERTS, C. F. (1959). A replica plating technique for the isolation of nutritionally exacting mutants of a filamentous fungus (Aspergillus nidulans). Journal of General Microbiology 20, 540-548.

Scazzocchio, C. (1974). The genetic determination of molybdoflavoenzymes in Aspergillus nidulans. Journal of Less-Common Metals 36, 461-464.

Simpson, I. N. \& Caten, C. E. (1979). Induced quantitative variation for penicillin titre in clonal populations of Aspergillus nidulans. Journal of General Microbiology 110, 1-12.

Stauffer, J. F. \& BACKus, M. P. (1954). Spontaneous and induced variation in selected stocks of the Penicillium chrysogenum series. Annals of the New York Academy of Sciences 60, art. 1.

Stouthamer, A. H. (1967). Nitrate reduction in Aerobacter aerogenes. I. Isolation and properties of mutant strains blocked in nitrate assimilation and resistant against chlorate. Archiv für Mikrobiologie $56,68-75$. 
